\title{
RESEARCH
}

Open Access

\section{Associations of healthy lifestyles with cerebrospinal fluid biomarkers of Alzheimer's disease pathology in cognitively intact older adults: the CABLE study}

Xiao-He Hou ${ }^{1}$, Wei Xu' ${ }^{1}$, Yan-Lin Bi ${ }^{2}$, Xue-Ning Shen ${ }^{3}$, Ya-Hui Ma' ${ }^{1}$, Qiang Dong ${ }^{3}$, Lan $\operatorname{Tan}^{1}$ and Jin-Tai Yu ${ }^{3 *}$ (D)

\begin{abstract}
Objective: We aimed to investigate the associations between healthy lifestyles and Alzheimer's disease (AD) biomarkers in cerebrospinal fluid (CSF).
\end{abstract}

Methods: A total of 1108 cognitively intact individuals from Chinese Alzheimer's Biomarker and LifestylE (CABLE) study were examined to evaluate the associations of AD biomarkers with healthy lifestyle factors, including no current smoking, no harmful drinking, absence of social isolation, and regular physical activity. The participants were categorized into groups of favorable, intermediate, and unfavorable lifestyles according to the lifestyle factors. The associations between overall lifestyle and CSF biomarkers were also analyzed.

Results: Among cognitively intact older adults, those having more social engagement had lower CSF tau ( $p=$ $0.009)$ and $p$-tau $(p<0.001)$ than those who had social isolation. Regular physical activity was associated with higher CSF AB42 $(p=0.013)$ and lower levels of CSF tau $(p=0.036)$ and $p$-tau $(p=0.007)$. However, no significant associations were found of smoking status or alcohol intake with CSF biomarkers. When the overall lifestyle of the participants was evaluated by all the four lifestyle factors, favorable lifestyle profiles were related to lower levels of CSF tau $(p<0.001)$ and $p$-tau $(p<0.001)$.

Conclusions: These findings suggest that healthy lifestyles had a beneficial effect on AD pathology among cognitively intact elders.

Keywords: Alzheimer's disease, Lifestyle, Social isolation, Physical activity, Cerebrospinal fluid, Biomarker

\footnotetext{
* Correspondence: jintai_yu@fudan.edu.cn

${ }^{3}$ Department of Neurology and Institute of Neurology, Huashan Hospital,

Shanghai Medical College, Fudan University, 12th Wulumuqi Zhong Road,

Shanghai 200040, China

Full list of author information is available at the end of the article
}

(c) The Author(s). 2021 Open Access This article is licensed under a Creative Commons Attribution 4.0 International License, which permits use, sharing, adaptation, distribution and reproduction in any medium or format, as long as you give appropriate credit to the original author(s) and the source, provide a link to the Creative Commons licence, and indicate if changes were made. The images or other third party material in this article are included in the article's Creative Commons licence, unless indicated otherwise in a credit line to the material. If material is not included in the article's Creative Commons licence and your intended use is not permitted by statutory regulation or exceeds the permitted use, you will need to obtain permission directly from the copyright holder. To view a copy of this licence, visit http://creativecommons.org/licenses/by/4.0/. The Creative Commons Public Domain Dedication waiver (http://creativecommons.org/publicdomain/zero/1.0/) applies to the data made available in this article, unless otherwise stated in a credit line to the data. 


\section{Introduction}

Alzheimer's disease (AD) is the most common cause of dementia, which becomes a great burden on patients and society [1]. AD risk can be influenced by both genetic and environmental factors. Recent analyses have shown that modifiable lifestyle factors might also influence the risk of $\mathrm{AD}$ [2]. It has been found that several healthy lifestyle factors are associated with lower risk of dementia [3-8]. And dementia risk can be lowered by the combination of favorable lifestyle factors $[9,10]$. In 2019, WHO published a guideline for the prevention of cognitive decline and dementia, which included tobacco cessation interventions, physical activity interventions, social activity interventions, and interventions for alcohol use disorders [11]. Estimates suggest that over a third of dementia cases could be prevented if currently established modifiable risk factors were eliminated at a population level [12].

Cerebrospinal fluid (CSF) $\beta$-amyloid 1-42 (A $\beta 42)$, total tau, and phosphorylated tau ( $\mathrm{p}$-tau) are validated biomarkers for AD. AD biomarkers may become abnormal more than 20 years before the diagnosis of dementia [13]. In the newly published NIA-AA research framework, the levels of CSF A $\beta 42$, tau and p-tau have been established as core AD biomarkers to define AD biologically [14]. There were some previous studies on the associations between several healthy lifestyle factors and AD biomarkers [15-17] which yielded inconsistent results. Whether lifestyle factors have an effect on AD core pathologies is less known.

We aimed to investigate the associations of common healthy lifestyles including no current smoking, no harmful drinking, absence of social isolation, and regular physical activity with CSF biomarkers of Alzheimer's disease pathology in a large sample of 1108 cognitively intact individuals.

\section{Materials and methods Study participants}

A total of 1108 cognitively normal individuals were included from the Chinese Alzheimer's Biomarker and LifestylE (CABLE) study [18]. CABLE is an ongoing large-scale study mainly focusing on Alzheimer's risk factors and biomarkers in Chinese Han population. Individuals were recruited at Qingdao Municipal Hospital, Shandong Province, China. All enrolled participants were Han Chinese aged between 40 to 90 years. The exclusion criteria include the following: (1) central nervous system infection, head trauma, epilepsy, multiple sclerosis, or other major neurological disorders; (2) major psychological disorders; (3) severe systemic diseases (e.g., malignant tumors); and (4) family history of genetic diseases other than AD. Demographic information and medical history were collected by an electronic medical record system. General cognitive function of participants was assessed by China-Modified Mini-Mental State Examination (CM-MMSE) and Montreal Cognitive Assessment. The cutoff values of MMSE were 19 for illiterate individuals, 22 for individuals with 1 to 6 years of education, and 26 for individuals with 7 or more years of education. The cutoff values of MoCA were 14 for illiterate individuals, 20 for individuals with 1 to 6 years of education, and 25 for individuals with 7 or more years of education in the screening of MCI [19].

\section{CSF AD biomarker measurements and APOE genotyping}

Cerebrospinal fluid of the participants was collected by lumbar puncture in $10 \mathrm{ml}$ polypropylene tubes before being sent to the lab within $2 \mathrm{~h}$. CSF samples were centrifuged at $2000 \mathrm{~g}$ for $10 \mathrm{~min}$. The thaw/freezing cycle was limited not to surpass 2 times. Baseline CSF $A \beta_{1-42}, A \beta_{1-}$ ${ }_{40}$, tau, and p-tau181 were determined with the ELISA kit (Innotest $\beta$-AMYLOID (1-42), $\beta$-AMYLOID (1-40), hTAU-Ag, and PHOSPHO-TAU (181p); Fujirebio, Ghent, Belgium) on the microplate reader (Thermo Scientific ${ }^{\text {тм }}$ Multiskan $^{\text {тм }}$ MK3). In quality control, all CSF samples were measured in duplicate. Duplicate measures which had a coefficient of variation $\geq 15 \%$ were excluded. Besides, extreme values which were 4-fold SD greater or smaller than the mean value were also removed from the analysis. Data were excluded in quality control for $\mathrm{A} \beta 42 \quad(n=162$, $14.6 \%)$, CSF A $\beta 40(n=198,17.9 \%)$, CSF tau $(n=92,8.3 \%)$, and CSF p-tau $(n=90,8.1 \%)$.

DNA was extracted from the blood samples using QIAamp DNA Blood Mini Kit (250) and amplified by the polymerase chain reaction. APOE alleles defined by rs7421 and rs429358 were genotyped by restriction fragment length polymorphism (RFLP) technology.

\section{Lifestyle assessment}

Lifestyle factors implicated in the risk of dementia were assessed by a comprehensive questionnaire, including (1) smoking status, (2) alcohol consumption, (3) social engagement, and (4) physical activity [11]. Each lifestyle factor was divided into two categories (healthy and unhealthy). Smoking status was categorized as current smoking or no current smoking. Alcohol consumption was categorized into harmful drinking group (pure alcohol $>25 \mathrm{~g} / \mathrm{d}$ for men and $>15 \mathrm{~g} / \mathrm{d}$ for women) and no or moderate drinking group according to the dietary guidelines for Chinese residents. Social engagement was categorized into social isolation and absence of social isolation according to the living arrangements (living alone, with spouse or with others) and close relationship with relatives, friends, and neighbors. If a participant was living alone or had no close relationship with relatives, friends, and neighbors, then we considered him or her as being socially isolated. As for physical activity, we 
assessed the frequency of physical activities and categorized into regular physical activity and lack of physical activity. Regular physical activity was regarded as a healthy lifestyle which was defined as moderate physical activity every day. Detailed questionnaire was provided in Additional file 1: Questionnaire used in the evaluation of healthy lifestyles.

\section{Statistical analysis}

The associations between healthy lifestyle factors and AD biomarkers were analyzed using multivariable linear regression. Age, gender, educational level, and APOE $\varepsilon 4$ status were included as covariates. The values of CSF AD biomarkers were transformed to achieve or approximate a normal distribution (Kolmogorov-Smirnov test $P>0.05)$ via "car" package of $\mathrm{R}$ software in case of skewed distribution. In subgroup analysis stratified by APOE $\varepsilon 4$ status, only age, gender, and educational level were included as covariates. The lifestyle of each participant was evaluated based on the assessments of the four lifestyle factors. In addition to consideration of their categories on each individual lifestyle variable, the lifestyle categories were defined by the number of healthy lifestyle factors the participants adhere to. The participants were categorized into favorable lifestyle group (4 healthy lifestyle factors), intermediate lifestyle group (3 healthy lifestyle factors), and unfavorable lifestyle group $(\leq 2$ healthy lifestyle factors). The associations between lifestyle categories and AD biomarkers were also analyzed using multivariable linear regression. Statistical analysis was carried out using $\mathrm{R}$ version 3.5.3.

\section{Results}

\section{Demographic and clinical characteristics of included participants}

A total of 1108 participants were enrolled in this study. The 1108 participants included 461 female participants (41.6\%). The baseline characteristics of the participants are summarized in Table 1 . In brief, the mean age of the included participants was $61.1 \pm 11.0$ years old. All the participants were cognitively unimpaired with a mean CM-MMSE score of $28.2 \pm 1.9$ (range 19 to 30). The mean MoCA score of the participants was $23.8 \pm 4.0$ (range 14 to 30 ).

\section{Associations between healthy lifestyle factors and CSF AD biomarkers}

The results are presented in Table 2. As for the factor of social engagement, after adjusting for age, sex, educational level, and APOE $\varepsilon 4$ status, participants without social isolation showed lower levels of CSF tau ( $p=$ $0.009)$ and $\mathrm{p}$-tau $(p<0.001)$ than those with social isolation (Fig. 1). Besides, participants engaging in regular physical activity had higher CSF A $\beta 42(p=0.013)$, as well
Table 1 Characteristics of study subjects

\begin{tabular}{ll}
\hline Characteristic & No. $(\boldsymbol{n}=1 \mathbf{1 0 8})$ \\
\hline Age (years) & $61.1 \pm 11.0(41$ to 89) \\
Sex (F/M) & $461 / 647$ \\
Education (years) & $9.8 \pm 4.4$ \\
CM-MMSE & $28.2 \pm 1.9$ \\
MoCA & $23.8 \pm 4.0$ \\
${ }^{*}$ APOE $\varepsilon 4$ (carriers/non-carriers) & $161 / 800$ \\
${ }^{*}$ CSF A 42 (pg/ml) & $167.6 \pm 79.5$ \\
${ }^{*}$ CSF A 40 (pg/ml) & $5981.8 \pm 2728.5$ \\
${ }^{*}$ CSF tau (pg/ml) & $171.3 \pm 76.1$ \\
${ }^{*}$ CSF p-tau (pg/ml) & $36.8 \pm 9.1$ \\
Healthy lifestyle factors ( $n, \%)$ & \\
No current smoking & $888(80.1 \%)$ \\
No or moderate drinking & $951(85.8 \%)$ \\
Regular physical activity & $275(24.8 \%)$ \\
Absence of social isolation & $868(78.3 \%)$ \\
No. of healthy lifestyle factors $(n, \%)$ & \\
0 & $9(0.8 \%)$ \\
1 & $84(7.6 \%)$ \\
2 & $302(27.3 \%)$ \\
4 & $558(50.4 \%)$ \\
\hline
\end{tabular}

Summarized as mean \pm standard deviation (SD) for continuous data and count for categorical data. Abbreviations: CSF, cerebrospinal fluid; MMSE, Mini-Mental State Examination; $\mathrm{p}$-tau, phosphorylated tau

* Data were missing for CSF A 42 ( $n=162,14.6 \%)$, CSF A 40 ( $n=198,17.9 \%)$, CSF tau $(n=92,8.3 \%)$, CSF p-tau $(n=90,8.1 \%)$, and APOE $\varepsilon 4$ statues $(n=147,13.3 \%)$

as lower levels of CSF tau $(p=0.036)$ and p-tau ( $p=$ $0.007)$ compared to those with a lack of regular physical activity (Fig. 2). However, no significant associations were found of smoking status and alcohol intake with CSF biomarkers.

It has been reported that $\mathrm{CSF} A \beta 42 / \mathrm{A} \beta 40$, tau/A $\beta 42$, and $\mathrm{p}$-tau/A $\beta 42$ ratios are better predictors of brain amyloid deposition than themselves alone [20, 21]. Therefore, we also explored the associations between the four lifestyle factors and AD biomarkers. Only regular physical activity was found to be associated with lower CSF tau/A $\beta 42(p<0.001)$ and $\mathrm{p}$-tau/A 442 ratios $(p<$ 0.001 , Additional file 1: Supplementary Fig. 1). We did not find any association between other three healthy lifestyle factors and the ratios of AD biomarkers.

\section{Associations between healthy lifestyle categories and CSF AD biomarkers}

We then categorized the participants into favorable lifestyle group (4 healthy lifestyle factors), intermediate lifestyle group (3 healthy lifestyle factors) and unfavorable lifestyle group ( $\leq 2$ healthy lifestyle factors). The CM- 
Table 2 Association between lifestyle factors and AD biomarkers

\begin{tabular}{|c|c|c|c|c|}
\hline & Current smoking & & $P^{*}$ & $P^{\#}$ \\
\hline & Yes $(n=220)$ & No $(n=888)$ & & \\
\hline CSF Aß42 & $162.25 \pm 71.75$ & $169.01 \pm 81.40$ & 0.47 & 0.17 \\
\hline CSF tau & $170.81 \pm 70.35$ & $171.43 \pm 77.54$ & 0.78 & 0.29 \\
\hline \multirow[t]{3}{*}{ CSF p-tau } & $36.57 \pm 8.57$ & $36.89 \pm 9.23$ & 0.83 & 0.47 \\
\hline & Alcohol consumption & & & \\
\hline & Harmful drinking $(n=157)$ & No or moderate drinking $(n=951)$ & & \\
\hline CSF A 42 & $178.53 \pm 94.72$ & $165.82 \pm 76.65$ & 0.35 & 0.44 \\
\hline CSF tau & $175.84 \pm 80.03$ & $170.55 \pm 75.48$ & 0.63 & 0.12 \\
\hline \multirow[t]{3}{*}{ CSF p-tau } & $37.11 \pm 10.00$ & $36.79 \pm 8.95$ & 0.97 & 0.35 \\
\hline & Absence of social isolation & & & \\
\hline & No $(n=240)$ & Yes $(n=868)$ & & \\
\hline CSF Aß42 & $175.89 \pm 89.94$ & $165.33 \pm 76.30$ & 0.27 & 0.19 \\
\hline CSF tau & $188.17 \pm 76.40$ & $166.67 \pm 75.44$ & $<0.01$ & $<0.01$ \\
\hline \multirow[t]{3}{*}{ CSF p-tau } & $39.11 \pm 9.09$ & $36.21 \pm 9.01$ & $<0.01$ & $<0.01$ \\
\hline & Regular physical activity & & & \\
\hline & No $(n=833)$ & Yes $(n=275)$ & & \\
\hline CSF A $A 42$ & $163.96 \pm 76.65$ & $178.96 \pm 87.03$ & 0.03 & 0.01 \\
\hline CSF tau & $173.73 \pm 78.20$ & $164.03 \pm 69.15$ & 0.10 & 0.04 \\
\hline CSF p-tau & $37.25 \pm 9.32$ & $35.57 \pm 8.28$ & 0.01 & $<0.01$ \\
\hline
\end{tabular}

*Unadjusted

\#Adjusted for age, sex, educational level, and APOE ع4 status

MMSE and MoCA scores were not significantly different among the three groups ( $p=0.38$ for CM-MMSE and $p=$ 0.22 for MoCA). The levels of CSF tau and $\mathrm{p}$-tau were found to be reduced across lifestyle categories from unfavorable lifestyle group to favorable lifestyle group $(p<$ 0.01 for CSF tau and p-tau, Additional file 1: Supplementary Table 1). CSF A $\beta 42$ levels were not significantly different among participants with different lifestyle profiles $(p=0.55)$.

When the participants were divided into APOE $\varepsilon 4$ carriers and $\mathrm{APOE} \varepsilon 4$ non-carriers, the associations of lifestyle categories with CSF tau and p-tau were found in both APOE $\varepsilon 4$ carriers and APOE $\varepsilon 4$ non-carriers (Additional file 1: Supplementary Table 1). In our study,

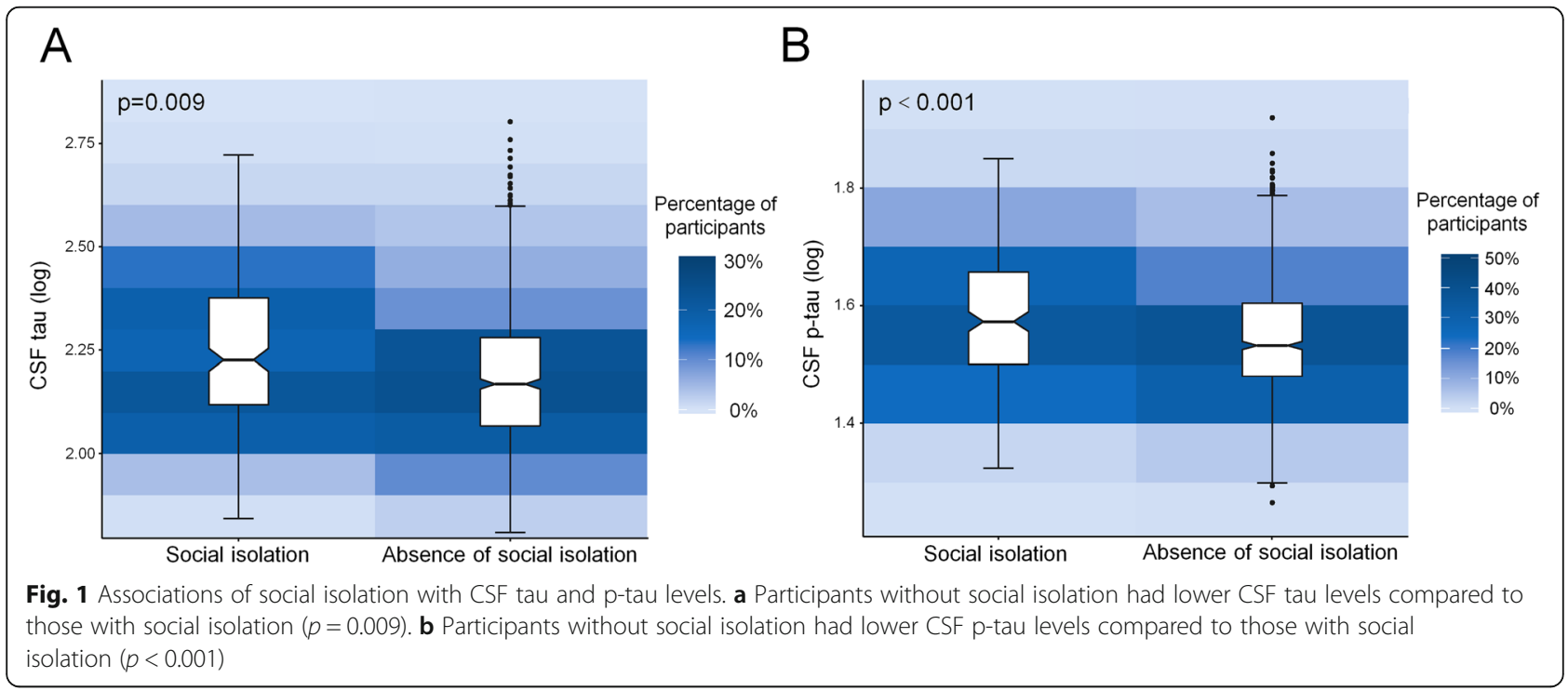



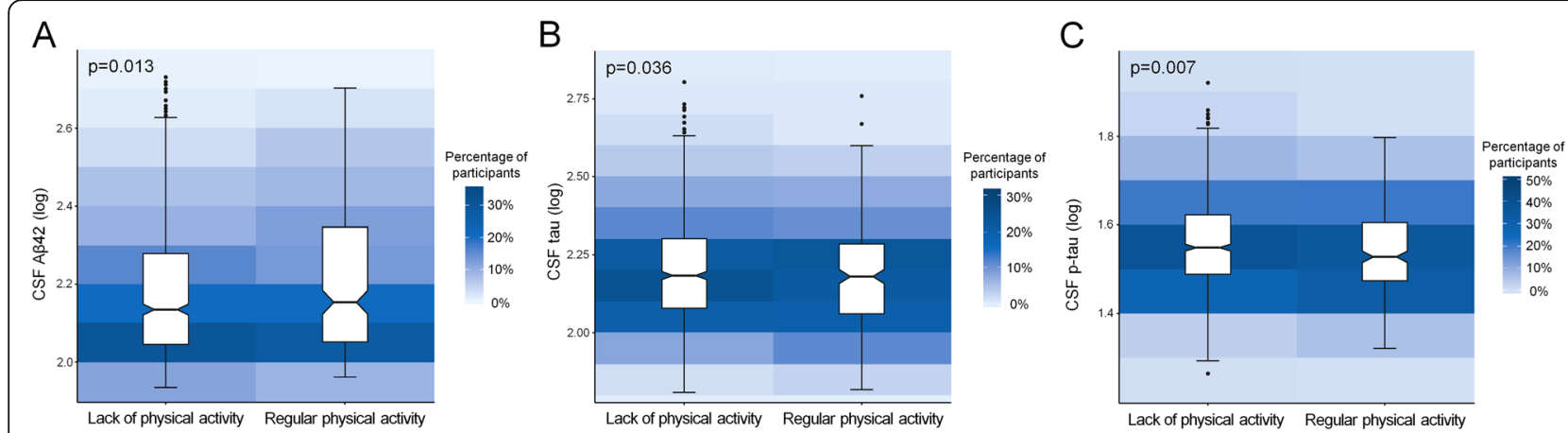

Fig. 2 Associations of physical activity with CSF A 42 and p-tau levels. Participants who were physically active had higher CSF AB42 levels (a), as well as lower CSF tau (b) and p-tau levels (c) compared to those who had a lack of regular physical activity

APOE $\varepsilon 4$ status was also found to be associated with CSF p-tau levels. APOE $\varepsilon 4$ carriers had higher CSF p-tau levels than APOE $\varepsilon 4$ non-carriers $(p=0.015)$. Therefore, we classified the participants into six groups according to their APOE $\varepsilon 4$ status and lifestyle categories. When APOE $\varepsilon 4$ status and lifestyle categories were combined, both of low genetic risk (APOE $\varepsilon 4$ negative) and favorable lifestyle were associated with decreased CSF p-tau levels (Fig. 3).

The associations of lifestyle categories with CSF A $\beta 42 /$ $\mathrm{A} \beta 40$, tau/A $\beta 42$, and $\mathrm{p}$-tau/A $\beta 42$ ratios were also analyzed. CSF tau/A $\beta 42$ and $\mathrm{p}$-tau/A $\beta 42$ ratios were found to be reduced across lifestyle categories in all participants as well as in both APOE subgroups (Additional file 1: Supplementary Table 2).

We then only included regular physical activity and social engagement in the analysis because smoking status and harmful alcohol intake were not independently associated with CSF AD biomarkers. The participants were classified into three groups according to the number of the two healthy lifestyles participants adhere to (having both lifestyles, having one lifestyle and having no healthy lifestyle). As expected, participants with more healthy lifestyles had lower CSF tau and p-tau levels $(p<0.01$ for CSF tau and p-tau, Additional file 1: Supplementary Table 3 ). These results indicated that regular physical activity and social engagement could significantly influence $\mathrm{AD}$ biomarkers. In addition, we also performed an interaction analysis. An interaction was found between regular physical activity and social engagement in the influence of CSF p-tau $(p=0.04$, Additional file 1: Supplementary Table 4).

\section{Discussion}

In the present study, we revealed beneficial effects of social engagement and physical activity on AD pathology. Individuals who had social engagement had significantly lower levels of CSF tau and p-tau than those who had social isolation. Regular physical activity was associated with higher levels of CSF A $\beta 42$, as well as lower levels of

\begin{tabular}{|c|c|c|c|c|}
\hline Subgroups & $\begin{array}{c}\text { No. of } \\
\text { participants }\end{array}$ & $\begin{array}{c}\text { CSF p-tau } \\
\text { (normalized) }\end{array}$ & Coefficients $(95 \% \mathrm{Cl})$ & $p$ value \\
\hline \multicolumn{5}{|l|}{ APOE $\varepsilon 4$ carriers } \\
\hline Unfavorable lifestyle & 56 & $1.68 \pm 0.04$ & Reference & - \\
\hline Intermediate lifestyle & 71 & $1.67 \pm 0.04$ & $-0.009(-0.022 \sim 0.003)$ & 0.134 \\
\hline Favorable lifestyle & 22 & $1.65 \pm 0.04$ & $-0.019(-0.038 \sim-0.001)$ & 0.035 \\
\hline \multicolumn{5}{|l|}{ APOE $\varepsilon 4$ non-carriers } \\
\hline Unfavorable lifestyle & 256 & $1.67 \pm 0.04$ & $-0.010(-0.022 \sim-0.000)$ & 0.050 \\
\hline Intermediate lifestyle & 382 & $1.66 \pm 0.04$ & $-0.015(-0.025 \sim-0.004)$ & 0.005 \\
\hline Favorable lifestyle & 112 & $1.65 \pm 0.04$ & $-0.024(-0.036 \sim-0.012)$ & $<0.001$ \\
\hline \multicolumn{5}{|c|}{ 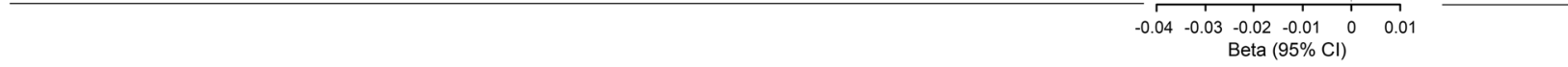 } \\
\hline
\end{tabular}


CSF tau and p-tau. These results are consistent with previous studies demonstrating beneficial effects of social engagement and physical activity on AD risk and cognitive function [6, 22, 23]. In addition, favorable lifestyle profiles evaluated by the four healthy lifestyles were related to lower CSF tau $(p<0.001)$ and p-tau $(p<0.001)$ levels.

Although social engagement is an important factor associated with AD risk, the associations of social engagement with $\mathrm{AD}$ biomarkers have rarely been reported. Donovan et al. showed that individuals who had greater feelings of loneliness had more cortical amyloid burden in a cross-sectional study [24]. But the authors indicated that loneliness might be a symptom rather than a cause of amyloid accumulation. Reijis et al. investigated the effects of later life lifestyle factors on AD biomarkers using a cohort of SCD and MCI patients. But they found no association between social activity and AD biomarkers [15]. In the current study, we found that social engagement, which was evaluated by living arrangements and self-reported intimate relationships, was associated with lower levels of CSF tau and p-tau. This association has not been reported before. It has been shown that brainderived neurotrophic factor (BDNF) levels are increased in individuals with more social support [25]. BDNF was found to have protective effects against tau-related neurodegeneration [26]. Social engagement may protect against adverse changes in AD biomarkers by increasing the production of BDNF. Further research is required on the mechanisms of social engagement in AD pathology.

More studies focused on physical exercise than social activity and demonstrated physical exercise could influence AD biomarkers. The effects of physical activity on AD biomarkers were revealed in animal models of AD [27, 28]. Accumulating evidence from cohort and cross-sectional studies with human participants has suggested that physical activity is beneficial to promoting a favorable profile of AD biomarkers in humans [16, 29-32]. It is worth noting that moderate but not vigorous physical activity had beneficial effects on dementia [31, 33]. The participants included in our study were older adults. Most of the participants did not have vigorous physical activity in their daily life. With a large sample size, our study further confirmed the associations of physical activity with decreased $A \beta 42$ and tau burden. In addition to CSF tau and p-tau, physical activity also had an effect on CSF $A \beta 42$, tau/A $\beta 42$, and $p$-tau/A $\beta 42$ ratios, which is different from social engagement. Several possible mechanisms regarding how physical activity is involved in AD pathology have been proposed. Physical activity could modulate selective biochemical changes [34], including the levels of high density lipoprotein, triglyceride and insulin, all of which may play a role in the production and/or clearance of $A \beta$ [35]. These might be one of the reasons why physical activity could influence CSF A $\beta$ levels. Besides, physical activity may protect against $\mathrm{AD}$ pathology by increasing cerebral blood flow or the production of BDNF [36].

Smoking and alcohol intake have been associated with $\mathrm{AD}$ as well [3]. Cerebral oxidative stress is a potential mechanism in which smoking elevates $\mathrm{AD}$ risk. It has been reported that oxidative stress could promote abnormal tau phosphorylation in the brain [37], but the association between CSF p-tau and smoking has not been reported. We did not find any difference in the levels of $\mathrm{A} \beta 42, \mathrm{t}$ tau, or $\mathrm{p}$ tau between current smoking group and no current smoking group in this study, which suggested that smoking might contribute to $\mathrm{AD}$ risk by brain oxidative damage rather than promoting AD pathology. Kok et al. reported an association between beer drinking and decreased $A \beta$ immunoreactivity in the brain [38]. But they did not find any association between the amount of alcohol consumed and $\mathrm{A} \beta$ aggregation. $\mathrm{A}$ dose-response association between alcohol intake and the risk of dementia has been reported [39]. Light-tomoderate alcohol consumption could lower the risk of dementia. However, it is not recommended for individuals having no alcohol consumption to start drinking in consideration of other health risks in WHO guidelines. Therefore, we considered no harmful drinking rather than moderate drinking as a healthy lifestyle. Similar to smoking, no significant associations were found of alcohol intake with CSF biomarkers.

The overall effect of the combination of lifestyle factors on AD biomarkers has not been reported. In our study, we categorized the participants into three groups (favorable, intermediate, and unfavorable lifestyle groups) according to the number of healthy lifestyle factors the participants adhered to. Consistent with previous studies showing that favorable lifestyles were associated with AD risk $[9,10]$, our study revealed the associations between healthy lifestyles and AD biomarkers including CSF tau and p-tau. Besides, more favorable lifestyles could reduce CSF tau and p-tau levels in both APOE $\varepsilon 4$ carriers and non-carriers. The results indicated that adhering to a healthy lifestyle was a potential way to prevent AD in early stage in spite of APOE $\varepsilon 4$ status. In the analysis only using regular physical activity and social engagement in the evaluation of healthy lifestyles, we also found significant associations of healthy lifestyles with CSF tau and p-tau. These results suggested that physical activity and social engagement might be the main factors which could influence AD biomarkers. We also found an interaction between regular physical activity and social engagement, which indicated that participation in physical activity and social engagement at the same time might have better effects on $\mathrm{AD}$ prevention. 
The mean educational level of the participants was 9.8 years in our study, which was lower than those of many other cohorts such as ADNI. Because some of the elders in China did not have chance to receive formal education when they were young, individuals with a high educational level tend to have a healthy lifestyle. We also found a positive association between years of education and healthy lifestyles. And only $14 \%$ of the participants had a favorable lifestyle in our study. Further studies are still needed to investigate the associations between lifestyles and biomarkers with more participants having a favorable lifestyle.

\section{Limitations}

There are some limitations in this study. The lifestyle factors were self-reported in our study. Physical activity was not measured objectively. Besides, we lacked validated scales to measure social engagement. In addition, the cross-sectional studies can reveal the associations between lifestyles and AD biomarkers, but cannot prove causal relationships. The follow-up study of CABLE participants has already been initiated. The causal relationships between lifestyle and AD biomarkers will be investigated in our future studies.

\section{Conclusions}

In conclusion, our present study revealed the associations of social isolation and physical activity with cerebrospinal fluid biomarkers of Alzheimer's disease pathology in cognitively intact older adults. These results provided evidence for lifestyle interventions in $\mathrm{AD}$ prevention and strengthened the current recommendations from WHO on $\mathrm{AD}$ prevention.

\section{Abbreviations \\ AB42: $\beta$-amyloid 1-42; AD: Alzheimer's disease; CABLE: Chinese Alzheimer's Biomarker and LifestylE; CSF: Cerebrospinal fluid; CM-MMSE: China-Modified} Mini-Mental State Examination; p-tau: Phosphorylated tau

\section{Supplementary Information}

The online version contains supplementary material available at https://doi. org/10.1186/s13195-021-00822-7.

Additional file 1: Supplementary Fig. 1. Associations of physical activity with CSF tau/A 42 and p-tau/ A $\beta 42$ ratios. (A) Participants who were physically active had lower CSF tau/Aß42 compared to those who had a lack of physical activity $(p<0.001)$. (B) Participants who were physically active had lower $p$-tau/A 342 levels compared to those who had a lack of physical activity $(p<0.001)$. Supplementary Table 1. Association between lifestyle categories and CSF AD biomarkers; Supplementary Table 2. Association of lifestyle categories with CSF A $42 / A \beta 40$, tau/ $A \beta 42$ and p-tau/A 342 ratios; Supplementary Table 3. Association between lifestyle categories (defined by physical activity and social engagement) and CSF AD biomarkers. Supplementary Table 4. Interaction analysis between physical activity and social engagement. Questionnaire used in the evaluation of healthy lifestyles.

\section{Acknowledgements}

The authors thank all participants of the present study as well as all members of staff of the CABLE study for their role in data collection.

\section{Authors' contributions}

J-TY, LT, QD, and X-HH conceptualized and designed the study. X-NS, Y-HM, and $\mathrm{Y}$-LB collected and organized the data. WX and $\mathrm{X}-\mathrm{HH}$ analyzed and interpreted the data. X-HH wrote the first draft of the manuscript. All authors reviewed the manuscript. All authors read and approved the final manuscript.

\section{Funding}

This study was supported by grants from the National Natural Science Foundation of China (91849126), Shanghai Municipal Science and Technology Major Project (No.2018SHZDZX01), and ZIILab, Tianqiao and Chrissy Chen Institute, and the State Key Laboratory of Neurobiology and Frontiers Center for Brain Science of Ministry of Education, Fudan University.

\section{Availability of data and materials}

The datasets used and/or analyzed during the current study are available from the corresponding author on reasonable request.

\section{Declarations}

\section{Ethics approval and consent to participate}

The CABLE study was conducted in accordance with the Helsinki declaration, and the protocol for this study was approved by the Institutional Ethics Committee of Qingdao Municipal Hospital. Written informed consent was obtained from all participants.

\section{Consent for publication}

Not applicable.

\section{Competing interests}

The authors have no conflict of interest to report.

\section{Author details}

${ }^{1}$ Department of Neurology, Qingdao Municipal Hospital, Qingdao University, Qingdao, China. ²Department of Anesthesiology, Qingdao Municipal Hospital, Qingdao University, Qingdao, China. ${ }^{3}$ Department of Neurology and Institute of Neurology, Huashan Hospital, Shanghai Medical College, Fudan University, 12th Wulumuqi Zhong Road, Shanghai 200040, China.

Received: 23 November 2020 Accepted: 6 April 2021

Published online: 19 April 2021

\section{References}

1. Alzheimer's A. 2016 Alzheimer's disease facts and figures. Alzheimers Dement. 2016;12(4):459-509. https://doi.org/10.1016/j.jalz.2016.03.001.

2. Xu W, Tan L, Wang HF, Jiang T, Tan MS, Tan L, et al. Meta-analysis of modifiable risk factors for Alzheimer's disease. J Neurol Neurosurg Psychiatry. 2015;86(12):1299-306.

3. Durazzo TC, Mattsson N, Weiner MW. Alzheimer's disease neuroimaging I. smoking and increased Alzheimer's disease risk: a review of potential mechanisms. Alzheimers Dement. 2014;10(3 Suppl):S122-45. https://doi. org/10.1016/j.jalz.2014.04.009

4. Anstey KJ, Mack HA, Cherbuin N. Alcohol consumption as a risk factor for dementia and cognitive decline: meta-analysis of prospective studies. Am J Geriatr Psychiatry. 2009;17(7):542-55. https://doi.org/10.1097/JGP.0b013e31 $81 \mathrm{a} 2 \mathrm{fd} 07$.

5. Fratiglioni L, Wang HX, Ericsson K, Maytan M, Winblad B. Influence of social network on occurrence of dementia: a community-based longitudinal study. Lancet. 2000;355(9212):1315-9. https://doi.org/10.1016/S0140-673 6(00)02113-9.

6. Penninkilampi $\mathrm{R}$, Casey AN, Singh MF, Brodaty $H$. The association between social engagement, loneliness, and risk of dementia: a systematic review and meta-analysis. J Alzheimers Dis. 2018;66(4):1619-33. https://doi.org/1 $0.3233 /$ JAD-180439.

7. Hamer M, Chida Y. Physical activity and risk of neurodegenerative disease: a systematic review of prospective evidence. Psychol Med. 2009:39(1):3-11. https://doi.org/10.1017/S0033291708003681. 
8. Kivipelto M, Mangialasche F, Ngandu T. Lifestyle interventions to prevent cognitive impairment, dementia and Alzheimer disease. Nat Rev Neurol. 2018;14(11):653-66. https://doi.org/10.1038/s41582-018-0070-3.

9. Lourida I, Hannon E, Littlejohns TJ, Langa KM, Hypponen E, Kuzma E, et al. Association of lifestyle and genetic risk with incidence of dementia. Jama. 2019:322(5):430-7. https://doi.org/10.1001/jama.2019.9879.

10. Licher S, Ahmad S, Karamujic-Comic H, Voortman T, Leening MJG, Ikram MA, et al. Genetic predisposition, modifiable-risk-factor profile and longterm dementia risk in the general population. Nat Med. 2019;25(9):1364-9. https://doi.org/10.1038/s41591-019-0547-7.

11. World Health Organization. Risk Reduction of Cognitive Decline and Dementia: WHO Guidelines. Geneva: World Health Organization; 2019.

12. de Bruijn RF, Bos MJ, Portegies ML, Hofman A, Franco OH, Koudstaal PJ, et al. The potential for prevention of dementia across two decades: the prospective, population-based Rotterdam Study. BMC Med. 2015;13(1):132. https://doi.org/10.1186/s12916-015-0377-5.

13. Villemagne $V L$, Burnham $S$, Bourgeat $P$, Brown B, Ellis KA, Salvado O, et al. Amyloid beta deposition, neurodegeneration, and cognitive decline in sporadic Alzheimer's disease: a prospective cohort study. Lancet Neurol. 2013;12(4):357-67. https://doi.org/10.1016/S1474-4422(13)70044-9.

14. Jack CR Jr, Bennett DA, Blennow K, Carrillo MC, Dunn B, Haeberlein SB, et al. NIA-AA Research Framework: toward a biological definition of Alzheimer's disease. Alzheimers Dement. 2018;14(4):535-62. https://doi.org/10.1016/j.ja Iz.2018.02.018.

15. Reijs BLR, Vos SJB, Soininen H, Lotjonen J, Koikkalainen J, Pikkarainen M, et al. Association between later life lifestyle factors and Alzheimer's disease biomarkers in non-demented individuals: a longitudinal descriptive cohort study. J Alzheimers Dis. 2017;60(4):1387-95. https://doi.org/10.3233/JAD-1 70039.

16. Brown BM, Peiffer JJ, Taddei K, Lui JK, Laws SM, Gupta VB, et al. Physical activity and amyloid-beta plasma and brain levels: results from the Australian Imaging, Biomarkers and Lifestyle Study of Ageing. Mol Psychiatry. 2013;18(8):875-81. https://doi.org/10.1038/mp.2012.107.

17. Vemuri P, Lesnick TG, Przybelski SA, Knopman DS, Roberts RO, Lowe VJ, et al. Effect of lifestyle activities on Alzheimer disease biomarkers and cognition. Ann Neurol. 2012;72(5):730-8. https://doi.org/10.1002/ana.23665.

18. Hou XH, Bi YL, Tan MS, Xu W, Li JQ, Shen XN, et al. Genome-wide association study identifies Alzheimer's risk variant in MS4A6A influencing cerebrospinal fluid sTREM2 levels. Neurobiol Aging. 2019;84(241):e13-20.

19. Lu J, Li D, Li F, Zhou A, Wang F, Zuo X, et al. Montreal cognitive assessment in detecting cognitive impairment in Chinese elderly individuals: a population-based study. J Geriatr Psychiatry Neurol. 2011;24(4):184-90. https://doi.org/10.1177/0891988711422528.

20. Racine AM, Koscik RL, Nicholas CR, Clark LR, Okonkwo OC, Oh JM, et al. Cerebrospinal fluid ratios with Abeta42 predict preclinical brain betaamyloid accumulation. Alzheimers Dement. 2016;2:27-38.

21. Janelidze $\mathrm{S}$, Zetterberg $\mathrm{H}$, Mattsson $\mathrm{N}$, Palmqvist $\mathrm{S}$, Vanderstichele $\mathrm{H}$ Lindberg O, et al. CSF Abeta42/Abeta40 and Abeta42/Abeta38 ratios: better diagnostic markers of Alzheimer disease. Ann Clin Transl Neurol. 2016;3(3): 154-65. https://doi.org/10.1002/acn3.274.

22. Balouch S, Rifaat $\mathrm{E}$, Chen HL, Tabet N. Social networks and loneliness in people with Alzheimer's dementia. Int J Geriatr Psychiatry. 2019;34(5):66673. https://doi.org/10.1002/gps.5065.

23. Buchman AS, Boyle PA, Yu L, Shah RC, Wilson RS, Bennett DA. Total daily physical activity and the risk of AD and cognitive decline in older adults. Neurology. 2012; 78(17):1323-9. https://doi.org/10.1212MNL.0b013e3182535d35.

24. Donovan NJ, Okereke OI, Vannini P, Amariglio RE, Rentz DM, Marshall GA, et al. Association of higher cortical amyloid burden with loneliness in cognitively normal older adults. JAMA Psychiatry. 2016;73(12):1230-7. https://doi.org/10.1001/jamapsychiatry.2016.2657.

25. Salinas J, Beiser A, Himali JJ, Satizabal CL, Aparicio HJ, Weinstein G, et al. Associations between social relationship measures, serum brain-derived neurotrophic factor, and risk of stroke and dementia. Alzheimers Dement ( $N$ Y). 2017;3(2):229-37. https://doi.org/10.1016/j.trci.2017.03.001.

26. Jiao SS, Shen LL, Zhu C, Bu XL, Liu YH, Liu CH, et al. Brain-derived neurotrophic factor protects against tau-related neurodegeneration of Alzheimer's disease. Transl Psychiatry. 2016;6(10):e907. https://doi.org/10.103 8/tp.2016.186

27. Adlard PA, Perreau VM, Pop V, Cotman CW. Voluntary exercise decreases amyloid load in a transgenic model of Alzheimer's disease. J Neurosci. 2005; 25(17):4217-21. https://doi.org/10.1523/JNEUROSCI.0496-05.2005.
28. Liu HL, Zhao G, Zhang H, Shi LD. Long-term treadmill exercise inhibits the progression of Alzheimer's disease-like neuropathology in the hippocampus of APP/PS1 transgenic mice. Behav Brain Res. 2013;256:261-72. https://doi. org/10.1016/j.bbr.2013.08.008

29. Liang KY, Mintun MA, Fagan AM, Goate AM, Bugg JM, Holtzman DM, et al. Exercise and Alzheimer's disease biomarkers in cognitively normal older adults. Ann Neurol. 2010;68(3):311-8. https://doi.org/10.1002/ana.22096.

30. Stillman CM, Lopez OL, Becker JT, Kuller LH, Mehta PD, Tracy RP, et al. Physical activity predicts reduced plasma beta amyloid in the Cardiovascular Health Study. Ann Clin Transl Neurol. 2017;4(5):284-91. https://doi.org/10.1 002/acn3.397.

31. Law LL, Rol RN, Schultz SA, Dougherty RJ, Edwards DF, Koscik RL, et al. Moderate intensity physical activity associates with CSF biomarkers in a cohort at risk for Alzheimer's disease. Alzheimers Dement. 2018;10:188-95.

32. Muller S, Preische $O$, Sohrabi HR, Graber S, Jucker M, Ringman JM, et al. Relationship between physical activity, cognition, and Alzheimer pathology in autosomal dominant Alzheimer's disease. Alzheimers Dement. 2018; 14(11):1427-37. https://doi.org/10.1016/j.jalz.2018.06.3059.

33. Geda YE, Roberts RO, Knopman DS, Christianson TJ, Pankratz VS, Ivnik RJ, et al. Physical exercise, aging, and mild cognitive impairment: a populationbased study. Arch Neurol. 2010;67(1):80-6. https://doi.org/10.1001/a rchneurol.2009.297.

34. Young JC. Exercise prescription for individuals with metabolic disorders. Practical considerations. Sports Med. 1995;19(1):43-54. https://doi.org/10.21 65/00007256-199519010-00004

35. Bates KA, Sohrabi HR, Rodrigues M, Beilby J, Dhaliwal SS, Taddei K, et al. Association of cardiovascular factors and Alzheimer's disease plasma amyloid-beta protein in subjective memory complainers. J Alzheimers Dis. 2009;17(2):305-18. https://doi.org/10.3233/JAD-2009-1050.

36. Brown BM, Peiffer JJ, Martins RN. Multiple effects of physical activity on molecular and cognitive signs of brain aging: can exercise slow neurodegeneration and delay Alzheimer's disease? Mol Psychiatry. 2013: 18(8):864-74. https://doi.org/10.1038/mp.2012.162

37. Enciu AM, Gherghiceanu M, Popescu BO. Triggers and effectors of oxidative stress at blood-brain barrier level: relevance for brain ageing and neurodegeneration. Oxidative Med Cell Longev. 2013;2013:297512.

38. Kok EH, Karppinen TT, Luoto T, Alafuzoff I, Karhunen PJ. Beer drinking associates with lower burden of amyloid beta aggregation in the brain: Helsinki Sudden Death Series. Alcohol Clin Exp Res. 2016;40(7):1473-8. https://doi.org/10.1111/acer.13102.

39. Xu W, Wang H, Wan Y, Tan C, Li J, Tan L, et al. Alcohol consumption and dementia risk: a dose-response meta-analysis of prospective studies. Eur J Epidemiol. 2017;32(1):31-42. https://doi.org/10.1007/s10654-017-0225-3.

\section{Publisher's Note}

Springer Nature remains neutral with regard to jurisdictional claims in published maps and institutional affiliations.

Ready to submit your research? Choose BMC and benefit from:

- fast, convenient online submission

- thorough peer review by experienced researchers in your field

- rapid publication on acceptance

- support for research data, including large and complex data types

- gold Open Access which fosters wider collaboration and increased citations

- maximum visibility for your research: over $100 \mathrm{M}$ website views per year

At $\mathrm{BMC}$, research is always in progress.

Learn more biomedcentral.com/submissions 